\title{
Correlation of VLF-EM Data with Radiometric Measurements: Implications for Uranium Exploration around Beldih, South Purulia Shear Zone, India
}

\author{
Saurabh Mittal, S. P. Sharma, Arkoprovo Biswas, and D. Sengupta \\ Department of Geology \& Geophysics, Indian Institute of Technology Kharagpur, Kharagpur, West Bengal 721302, India \\ Correspondence should be addressed to Saurabh Mittal; saurabhmittal@gg.iitkgp.ernet.in
}

Received 22 October 2013; Revised 26 January 2014; Accepted 25 February 2014; Published 27 March 2014

Academic Editor: Michael S. Zhdanov

Copyright (C) 2014 Saurabh Mittal et al. This is an open access article distributed under the Creative Commons Attribution License, which permits unrestricted use, distribution, and reproduction in any medium, provided the original work is properly cited.

\begin{abstract}
This study is an attempt to correlate VLF-EM data with the radiometric measurements to decipher the subsurface structure and to locate uranium mineralization in the shear zone. The study area is around Beldih mine which is an open cast apatite mine located on the South Purulia Shear Zone. VLF method has been applied to map the structure and the presence of radioactive minerals has been delineated by the detection of high $\alpha$ and $\gamma$ counts with respect to the background radiations. High radiation counts and high surface $\gamma$ activity are found just above the higher apparent current-density zones in all the profiles studied, at various locations, indicating uranium and/or thorium mineralization as well as good correlation between these techniques.
\end{abstract}

\section{Introduction}

Radioactive minerals occur naturally in the geological environment associated with geological features like unconformity contact, veins, shear zones, and so forth $[1,2]$. The nature of mineralization varies from hydrothermal vein type, strata bound deposit, disseminated type, and brecciated complex in the form of vertical, dipping, and horizontal sheet type structures. This is dependent primarily on the prevailing geological environment and the valence state of uranium, respectively. In addition, the extinction coefficient of $\alpha$ and $\beta$ particles and $\gamma$ radiations determines the depth of investigation. Such shallow subsurface structures can be best delineated by very low frequency electromagnetic method due to its advantage in detecting conducting structures. Uranium, being a metal, is highly conducting and, therefore, its presence in the subsurface rocks provides an excellent conductivity contrast between its deposit and the neighboring formations [3, 4]. Moreover, to validate the presence of radioactive mineralization, radiometric survey is an essential aspect which can differentiate, with a better resolution, between a probable mineralization and that of an economic prospect. Their occurrences in outcrop enhance the background radiation of the area.

The present area of study is around an open cast mine in Beldih, which is known for apatite deposits and mainly consists of quartz-magnetite-apatite rocks, granite, quartzite, and so forth. This mine is located along the South Purulia Shear Zone (SPSZ). Low gravity, high magnetic anomaly, low resistivity, low self-potential, and shallow subsurface signature of uranium from bore hole has also been found in and around Beldih mine [5-7]. Considering these findings, our aim of the survey was to demarcate the actual structure of the uranium ore body and to trace its possible extension along the shear zone around Beldih mine. To achieve this, an integrated approach was applied, where very low frequency (VLF) electromagnetic and radiometric surveys were used together. Since the depth of investigation for VLF method depends on skin depth and for the radiometric method depends on extinction coefficient which in turn depends on the lithology of the area as well as on the energy of the associated particles, these measurements will throw some light in better correlation for uranium mineralization. Another added advantage of this integrated approach is their 


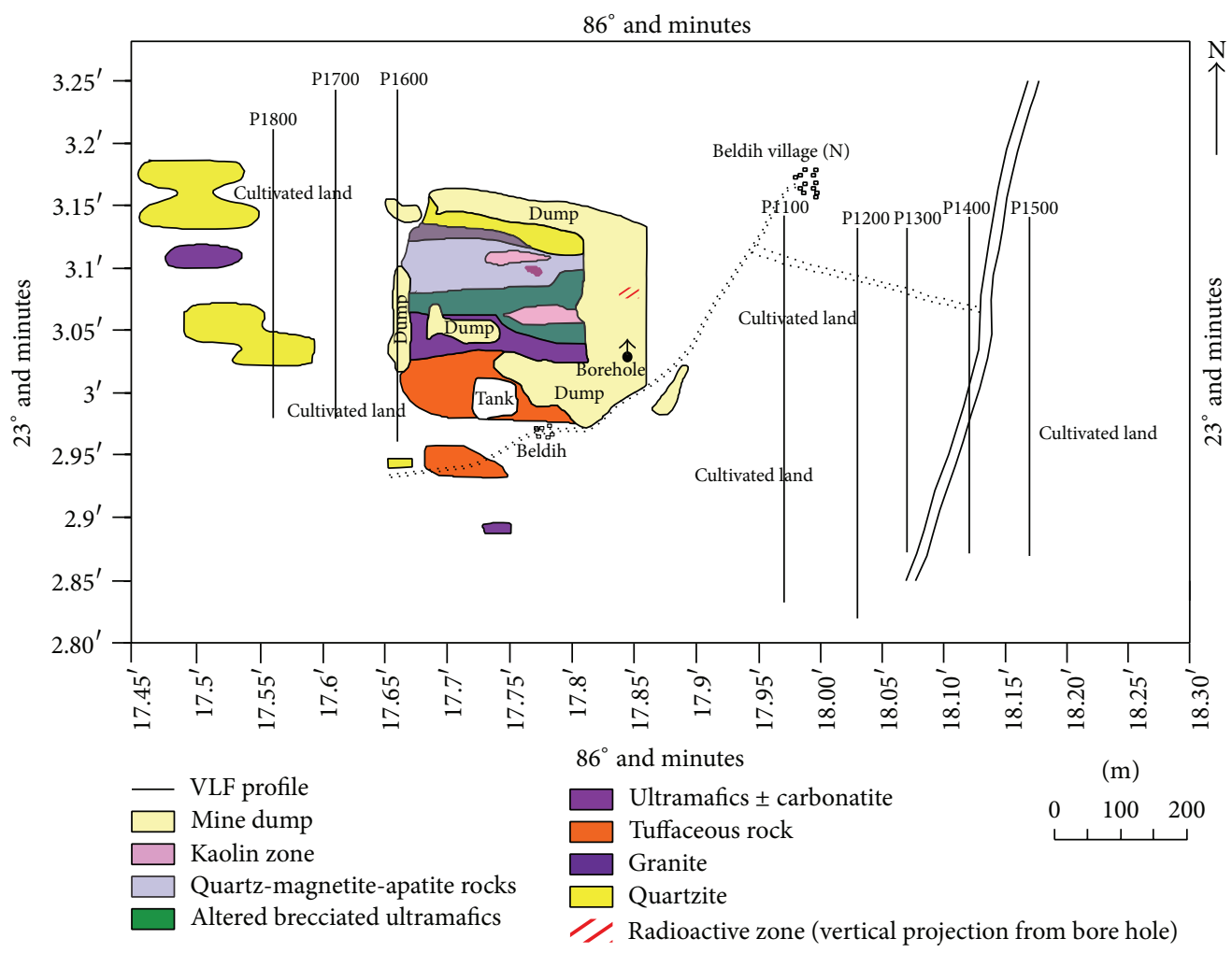

FIGURE 1: Geological map of Beldih mine (modified after [7]) showing VLF profiles (straight lines).

rapidness and cost-effectiveness and, hence, they can be used as a quick mapping and subsurface imaging tool for scanning structures associated with uranium mineralization.

\section{Geology of the Area}

Beldih mine is located in Purulia district of West Bengal, India, along the South Purulia Shear Zone (SPSZ). This forms a part of E-W to ESE-WNW trending Tamar-Porapahar lineament and it extends from Tamar, Ranchi district, Jharkhand, in the west to Porapahar, Bankura district, West-Bengal, in the east. The lineament vis-à-vis shear zone lies between the contact of Chotanagpur Granite Gneiss Complex (CGGC) in the north and Singhbhum Group in the south. The stratigraphic sequence of the Beldih area is represented by ultramafic rocks, chlorite-sericite schists, chlorite-mica schists, quartzites, alkali granites, amphibolites, and Chotanagpur granite gneiss [8,9]. Quartz-apatite-magnetite rocks, carbonatite, and syenites are some other significant rocks reported from Beldih region [9-12]. This part of the shear zone is also referred to as Beldih-Kutni shear zone; it is a small part of SPSZ where deformation is more intense, which crosscuts the boundaries of regional metamorphic zoning. The nature of the shear zone has been described as ductile to brittle-ductile $[13,14]$. The Beldih deposit is hosted by the rocks of amphibolite facies, but the rocks in shear zone are composed of chlorite schists and hydrothermally altered rocks. This mine is also well known for its apatite mining $[10,13]$ and, recently, presence of uranium deposits is also reported from this mine [7].

\section{Very Low Frequency Electromagnetic Survey}

Very low frequency method is a semipassive electromagnetic induction method which utilizes distant high power vertical transmitters as a source for the primary field. These transmitters are meant for long distance marine communications and situated on the coastal areas worldwide. They operate in the lower band $(15-30 \mathrm{kHz})$ of communication frequency. These signals travel a long distance and can be utilized for geophysical measurements several thousand $\mathrm{km}$ away from transmitters. Since the primary field is horizontal, VLF method is ideal for the investigation of vertical and dipping conducting structures in the subsurface. It is emphasized that, in principle, VLF method uses the highest frequency compared to other electromagnetic methods. The name "very low frequency" comes from the transmitter used for long distance marine communication. Indeed, $15-30 \mathrm{kHz}$ is very low with regard to other communication frequencies used in radio, $\mathrm{TV}$, and mobile communications.

The ABEM Wadi VLF instrument that utilizes only a magnetic field component was used for the present study. This instrument measures the ratio of the vertical component of the magnetic field $\left(H_{z}\right)$ which depends on the subsurface 


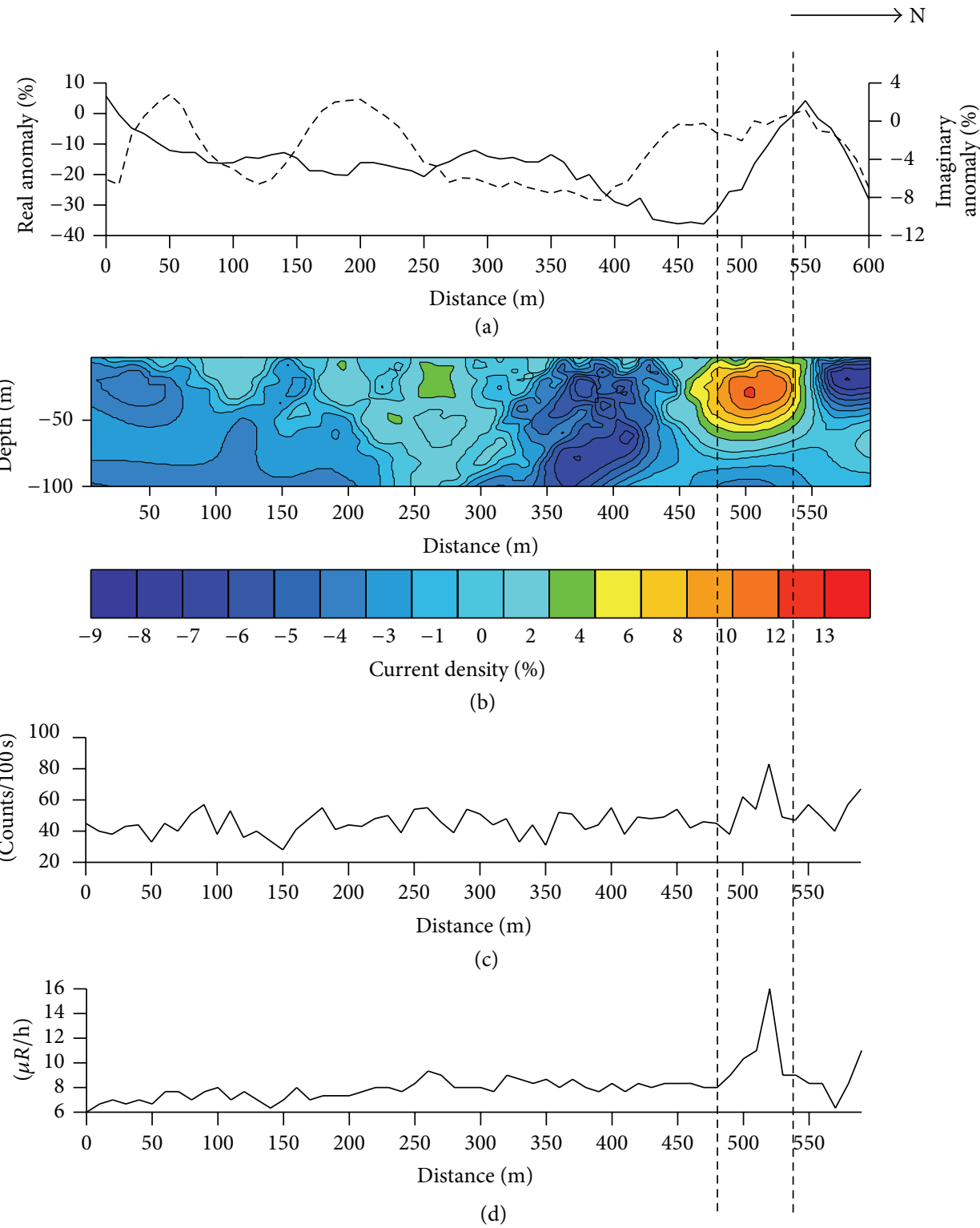

Figure 2: Profile P1100: (a) VLF anomaly (real by solid line and imaginary by dashed line), (b) pseudo current density cross-section along profile P1100, and (c) surface radiation and (d) surface gamma activity.

conductor and the horizontal component $\left(H_{x}\right)$ of the primary magnetic field, which depends mostly on the VLF transmitter.

If the geological strike is along $y$-axis and VLF transmitter is located in the direction of $Y$-axis from the point of observation, then the tilt angle $\alpha$, which is the inclination of the major axis of the polarization ellipse, and the ellipticity $e$, which is the ratio of the minor to the major axis of the ellipse, are calculated by the formulae [15]

$$
\begin{aligned}
\tan 2 \alpha & = \pm \frac{2\left(H_{z} / H_{x}\right) \cos \Delta \phi}{1-\left(H_{z} / H_{x}\right)^{2}}, \\
e & =\frac{H_{z} H_{x} \sin \Delta \phi}{H_{1}^{2}},
\end{aligned}
$$

where the phase difference $\Delta \phi=\phi_{z}-\phi_{x}$, in which $\phi_{z}$ is the phase of $H_{z}, \phi_{x}$ is the phase of $H_{x}$, and $H_{1}=\mid H_{z} e^{i \Delta \phi} \sin \alpha+$ $H_{x} \cos \alpha \mid$. The tangent of the tilt angle and the ellipticity are good approximations to the ratio of the real component of the vertical secondary magnetic field to the horizontal primary magnetic field and to the ratio of the quadrature component of the vertical secondary magnetic field to the horizontal primary field, respectively [16]. These quantities are called the real $(=\tan \alpha \times 100 \%)$ and imaginary $(=e \times 100 \%)$ anomalies, respectively, and they are normally expressed in percentage.

It is to be noted that real and imaginary VLF anomalies like other electromagnetic anomalies are also affected by different kinds of noises such as power line disturbances as well as cultural noises. In the present case, the study area 


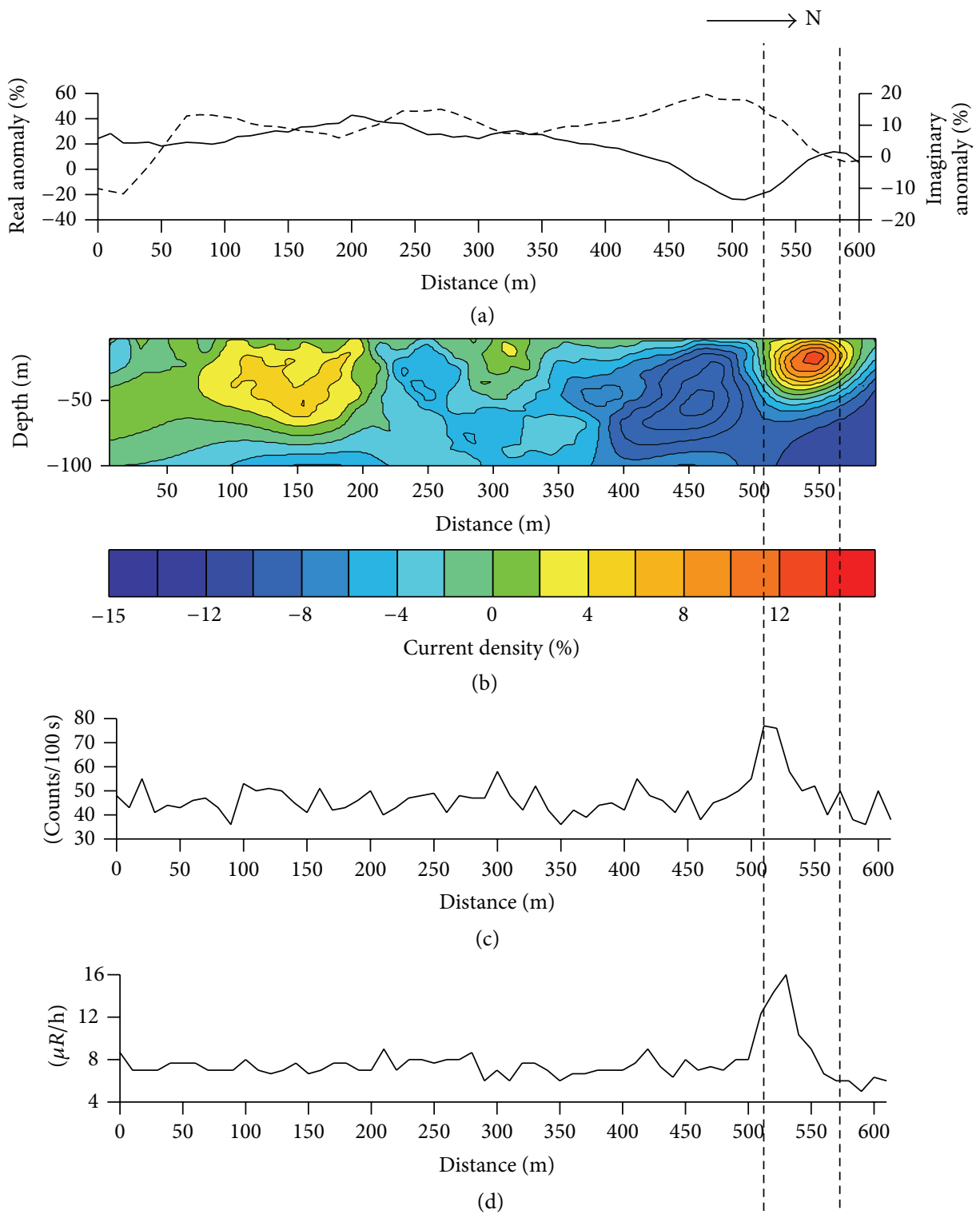

Figure 3: Profile P1200: (a) VLF anomaly (real by solid line and imaginary by dashed line), (b) pseudo current density cross-section along profile P1100, and (c) surface radiation and (d) surface gamma activity.

is quite remote and free from cultural noise but is affected by power line disturbances. However, the power distribution was absent during day time when the measurements were taken. Hence, VLF measurement is free from such noise also. Further, transmitter should be selected in the direction of geological strike and measurement should be made in a profile perpendicular to the known geological strike to attain maximum signal to noise ratio or least effect of noise on the actual data. ABEM Wadi instrument automatically corrects the observation, if transmitter direction is deviated \pm 10 degrees from the required direction. When transmitter direction is deviated by a large amount then a "bad tuning signal" is displayed on the monitor of the instrument.
Subsequently, orientation is adjusted accordingly and correct measurement is recorded. With these precautions in the instrument, the expected error in the measurements is less than 5\%.

The strike of the formation around the Beldih mine is approximately in the E-W direction; hence, a transmitter in E-W direction with frequency of $19.8 \mathrm{kHz}$ (located in Bombay, India) was selected for E-polarization measurements. VLF surveys were performed along eight profiles oriented in $\mathrm{N}-\mathrm{S}$ direction (Figure 1) (running from south to north). The data was acquired at $10 \mathrm{~m}$ intervals and, subsequently, data was first smoothed with 5-point averaging filter and then interpolated at $2 \mathrm{~m}$ intervals to increase the resolution. 

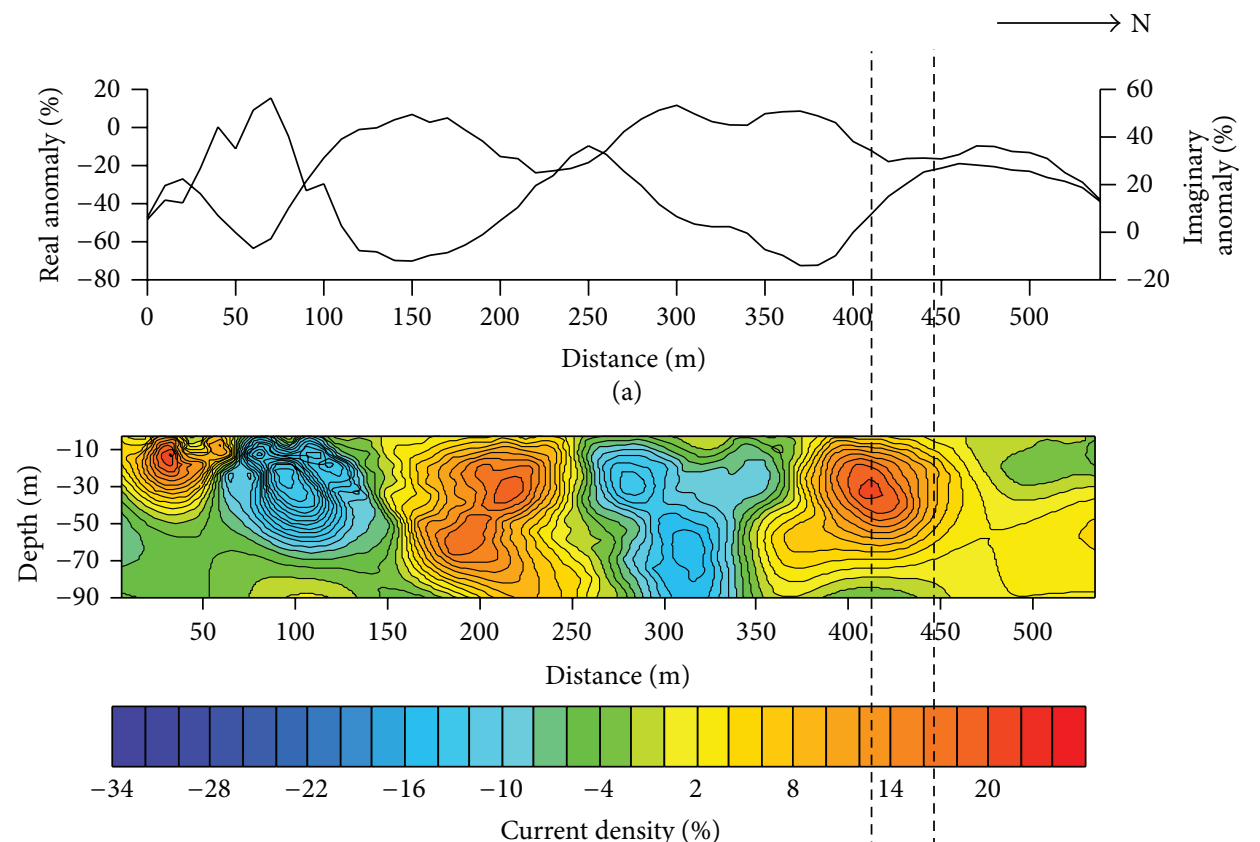

(b)

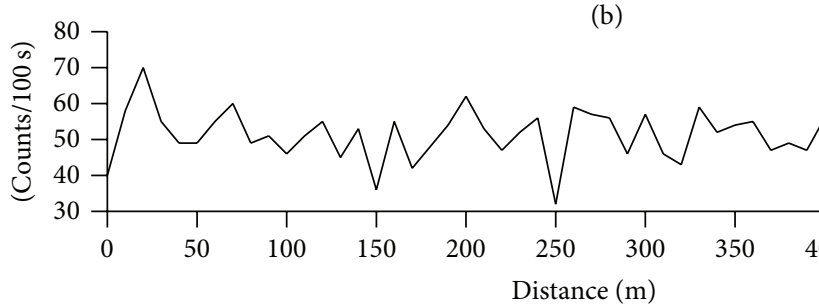

(c)

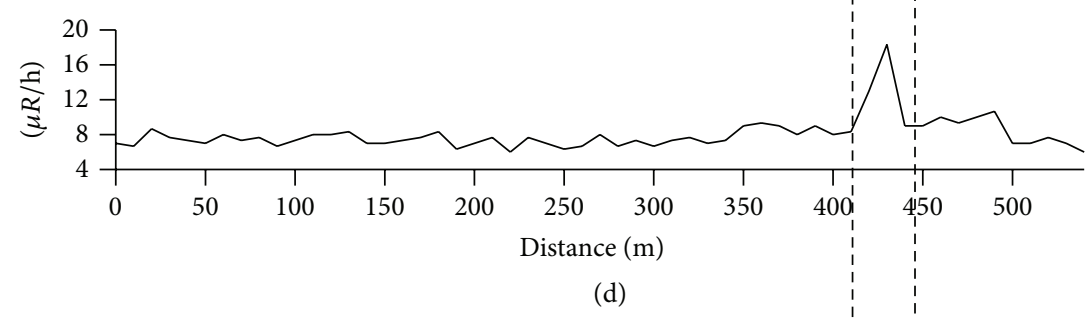

FIGURE 4: Profile P1300: (a) VLF anomaly (real by solid line and imaginary by dashed line), (b) pseudo current density cross-section along profile P1100, and (c) surface radiation and (d) surface gamma activity.

The above mentioned interpolated (Real and imaginary) data is transformed into apparent current density distribution in the subsurface which resembles the subsurface structure. Karous and Hjelt [17] developed a filtering technique to calculate apparent current density which produces a magnetic field identical to the measured field. If $H_{-3}, H_{-2}, H_{-1}, H_{0}, H_{1}$, $\mathrm{H}_{2}$, and $\mathrm{H}_{3}$ are the equispaced real or imaginary anomaly at locations $x_{-3}, x_{-2}, x_{-1}, x_{0}, x_{1}, x_{2}$, and $x_{3}$, respectively; the apparent current density at $x_{0}$ and depth $\Delta z=\Delta x$ can be computed from the following relation. Consider

$$
\begin{array}{r}
J_{a}\left(x_{0}\right)=\frac{2 \pi}{\Delta z}\left(-0.102 H_{-3}+0.059 H_{-2}-0.561 H_{-1}\right. \\
\left.+0.561 H_{1}-0.059 H_{2}+0.102 H_{3}\right) .
\end{array}
$$

Subsequently, apparent current density is computed along whole profile at depth $\Delta z=\Delta x$ by considering other observations along the profile in a systematic manner. Next, observation stations are selected with $2 \Delta x$ spacing and filtering is repeated to obtain apparent current density at depth $2 \Delta x$. This process is repeated to obtain apparent current density at various depths. The main limitation of this approach is apparent current density which gets truncated gradually with depth from both sides of the profile. This imaging technique yields $8 \%$ error in the estimation of the structure [17]. However, it is fast and accurate in depicting the subsurface structure and widely used for VLF data interpretation. We have used this imaging technique to produce apparent current density cross-sections in the present study. 


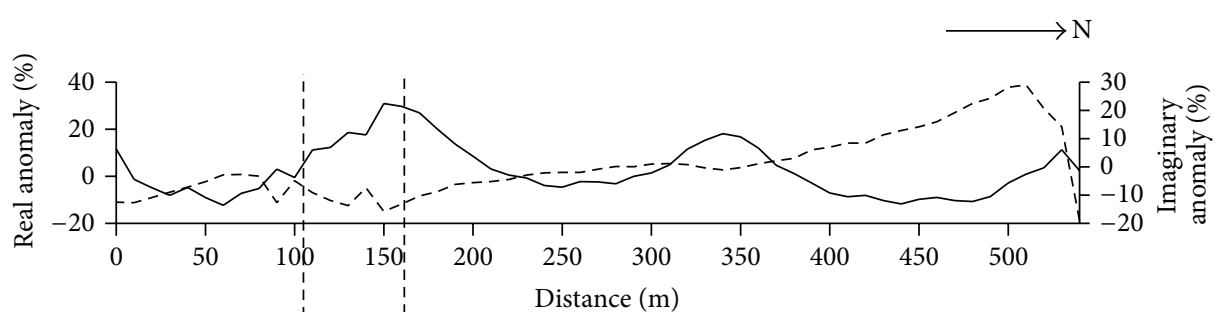

(a)

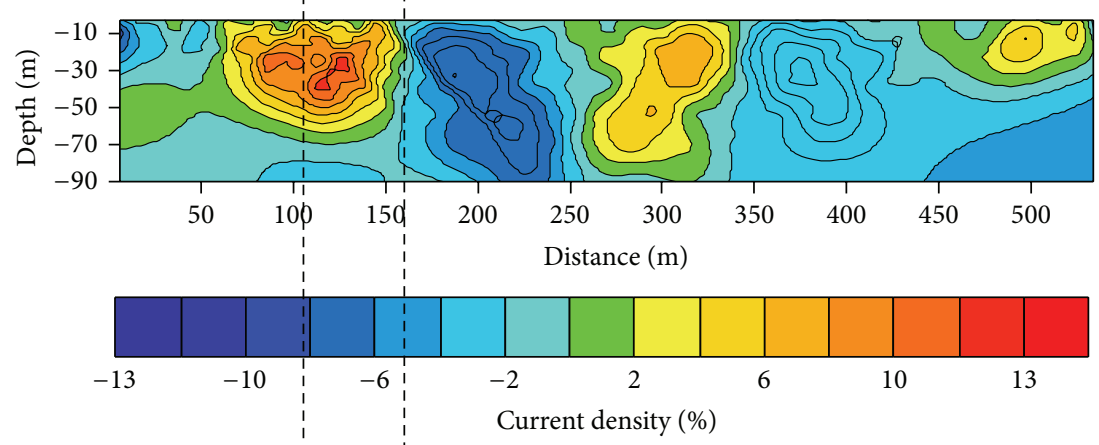

(b)

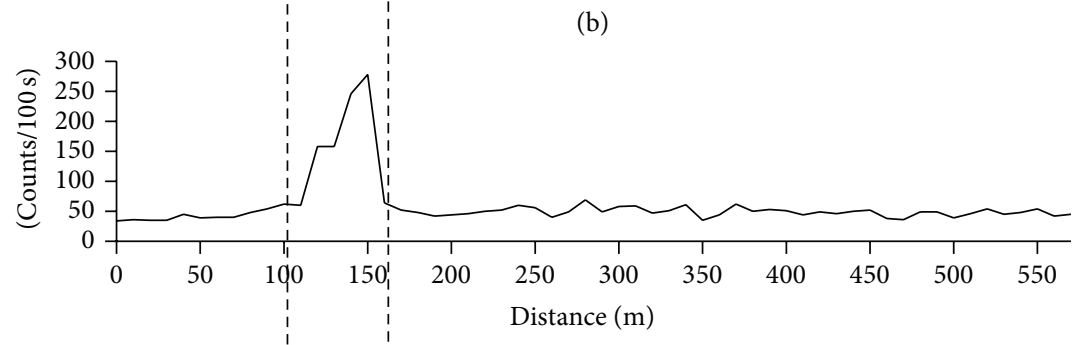

(c)

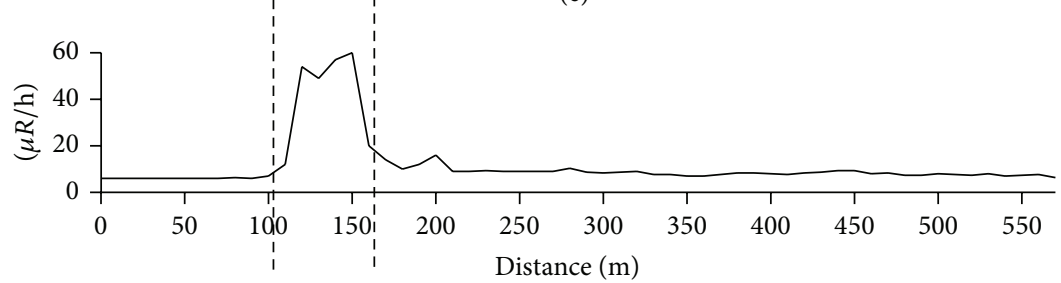

(d)

FIgURE 5: Profile P1400: (a) VLF anomaly (real by solid line and imaginary by dashed line), (b) pseudo current density cross-section along profile P1100, and (c) surface radiation and (d) surface gamma activity.

\section{Radiometric Survey}

Radiometric survey was carried out using Geiger-Muller counter to record total ambient surface radiations and Scintillation counter to note the surface gamma radiations along the eight selected profiles where VLF survey was performed. For better and point to point correlation with VLF data, radiometric data was collected at the same stations where VLF data was recorded, along all the profiles using GPS receivers. For precise and accurate measurements every radiometric measurement was repeated thrice.

4.1. Geiger-Muller Counter. Total surface radiations were measured using a portable pulsed GM (Geiger-Muller) counter at various locations along the selected profiles around the mine. The GM probe is comprised of a thin end window halogen-quenched counter which is capable of detecting alpha and beta particles and small amount of gamma radiations. It has a dead time of $200 \mu \mathrm{s}$. The window is $2 \mathrm{~cm}$ in diameter and is shielded with a $1 \mathrm{~cm}$ thick lead collar. The instrument is operated with five membrane push button switches and the display is a 6-digit LED.

For detailed radiometric survey, total radiation counts were measured at every $10 \mathrm{~m}$ intervals along the profiles, exactly where the VLF data was recorded. For each measurement, the sensor of GM counter was kept approximately $15 \mathrm{~cm}$ above the ground surface and operated for 100 seconds during data acquisition.

4.2. Scintillation Counter. For precise measurements of the $\gamma$ radiation, we have used a portable scintillator based counting 


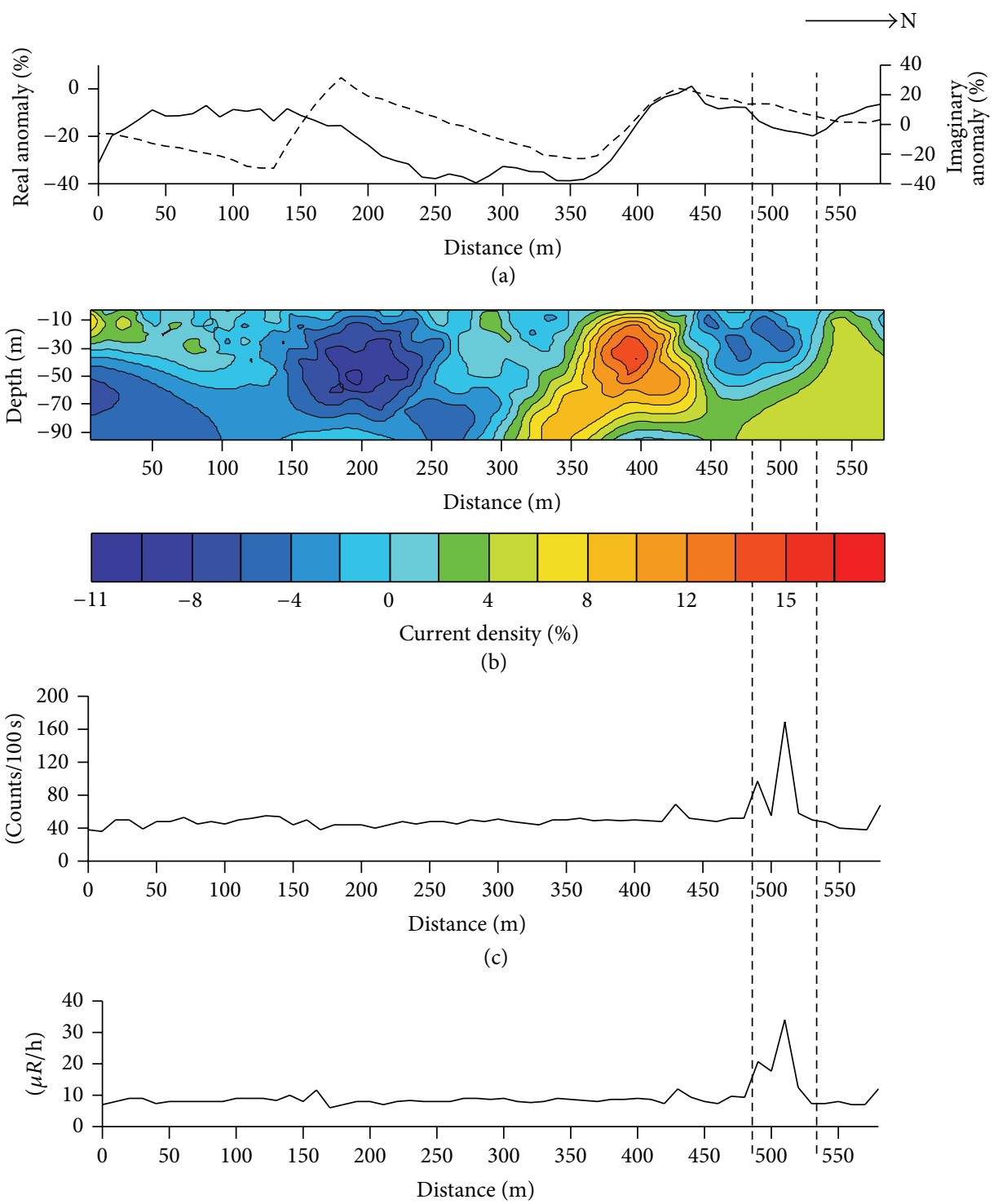

(d)

Figure 6: Profile P1500: (a) VLF anomaly (real by solid line and imaginary by dashed line), (b) pseudo current density cross-section along profile P1100, and (c) surface radiation and (d) surface gamma activity.

system. This Micro-R Survey Meter, Type-UR 705, is manufactured by Nucleonix Systems Private Limited, Hyderabad, India. It is designed around an integrally coupled $2.54 \times$ $2.54 \mathrm{~cm}$ scintillator coupled to a $2.54 \times 1.27 \mathrm{~cm}$ Photomultiplier Tube.

The measurements were taken during winter season in order to avoid the interference of gamma-emitting radon decay products [18]. The $\gamma$ measurements were undertaken $\sim 1 \mathrm{~m}$ above the ground surface and directly above the exposure to get a better solid angle. Each measurement was undertaken for more than 60 seconds and was repeated thrice for better precision and optimizing the subsequent interpretation in terms of the ambient radiation.

\section{Results}

On eastern side of the mine area, five profiles, namely, P1100, P1200, P1300, P1400, and P1500, covering around $600 \mathrm{~m}$ of distance (profile length) (Figure 1) were accomplished. On the western part of mine we took three profiles P1600, P1700, and P1800 covering $600 \mathrm{~m}$ of length (Figure 1). For interpretation of the subsurface geometry, apparent current density cross-sections with depths were made using the acquired VLF data along all the profiles. For this, the measured real anomalies were interpolated at $2 \mathrm{~m}$ interval and filtered using Karous-Hjelt filter [17]. These apparent current density cross-sections are presented in Figures 2-9 


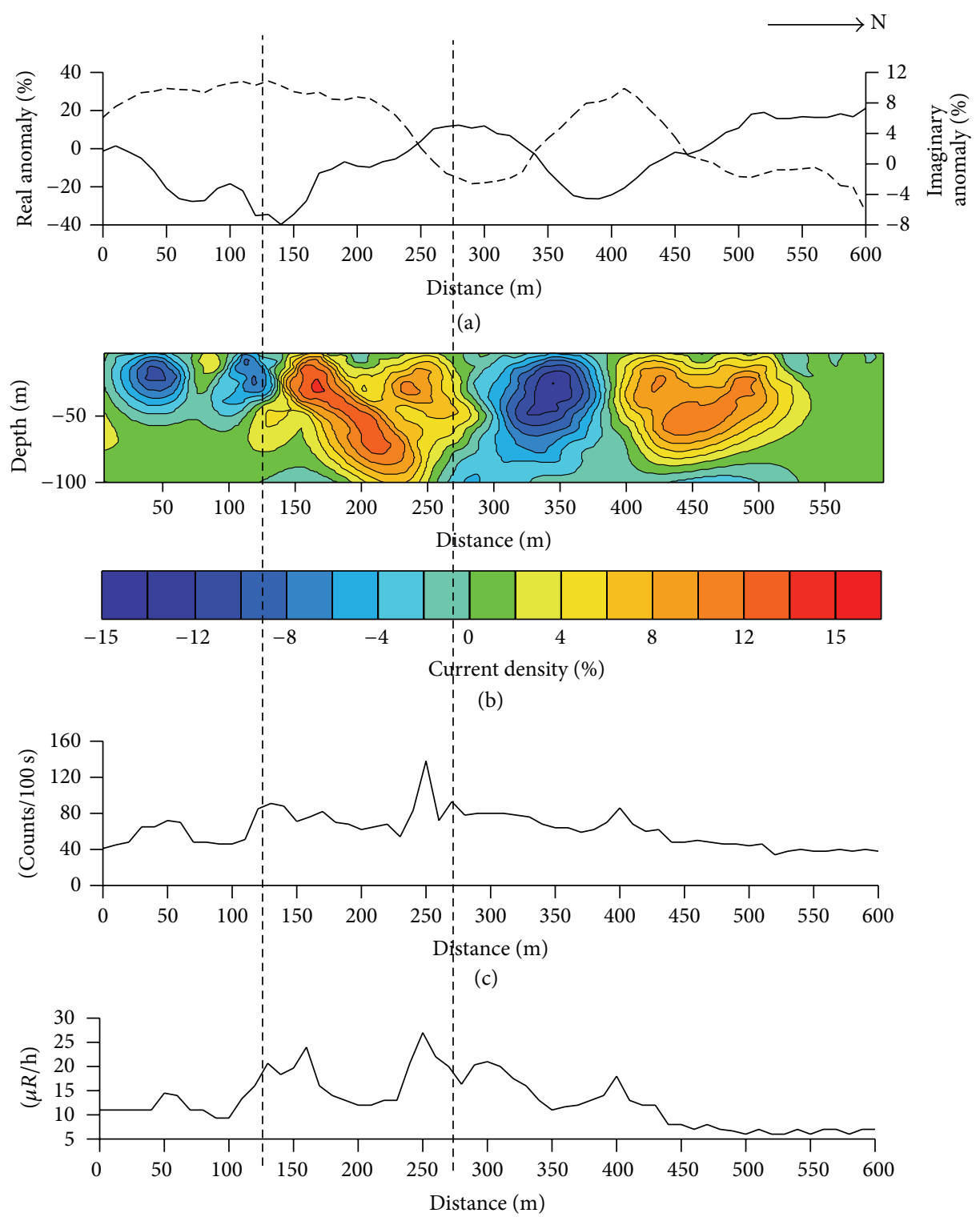

(d)

Figure 7: Profile P1600: (a) VLF anomaly (real by solid line and imaginary by dashed line), (b) pseudo current density cross-section along profile P1100, and (c) surface radiation and (d) surface gamma activity.

below the real and imaginary anomaly plots obtained from the VLF data acquired in the field. Results for surface gamma activity and total surface radiations are also shown as lineplots along with VLF anomaly for every individual profile (Figures 2-9). Background radiation level of the region is 40 counts $/ 100 \mathrm{sec}$ for surface radiations and $6-8 \mu \mathrm{R} / \mathrm{h}$ for surface gamma activity.

5.1. Profile 1 (P1100). The cross-over of real and imaginary anomaly line-plot along this profile indicates the presence of conductive zone between stations $500 \mathrm{~m}$ and $580 \mathrm{~m}$ (Figure 2(a)). This zone is clearly depicted in apparent current density cross-section (Figure 2(b)) by higher values between stations $460 \mathrm{~m}$ and $540 \mathrm{~m}$. Inclination of real anomaly curve and apparent current density contours indicate that this conductive structure is vertical and lying at shallow depth $(\sim 40 \mathrm{~m}$ below surface). Radiometric data suggest the presence of radiation more than the background levels above this conductive zone with peak value of $16 \mu \mathrm{R} / \mathrm{h}$ and 80 counts $/ 100 \mathrm{sec}$ for surface gamma activity and total radiations, respectively, at station $520 \mathrm{~m}$.

5.2. Profile 2 (P1200). Profile P1200 is parallel to and $96 \mathrm{~m}$ east of profile P1100 (Figure 3). The cross-over of real and imaginary VLF anomaly along this profile indicates the presence of conductive feature around station $550 \mathrm{~m}$ in the northern end of the profile and the slope of curve suggests it to be a thin inclined body occurring at shallow depth. 


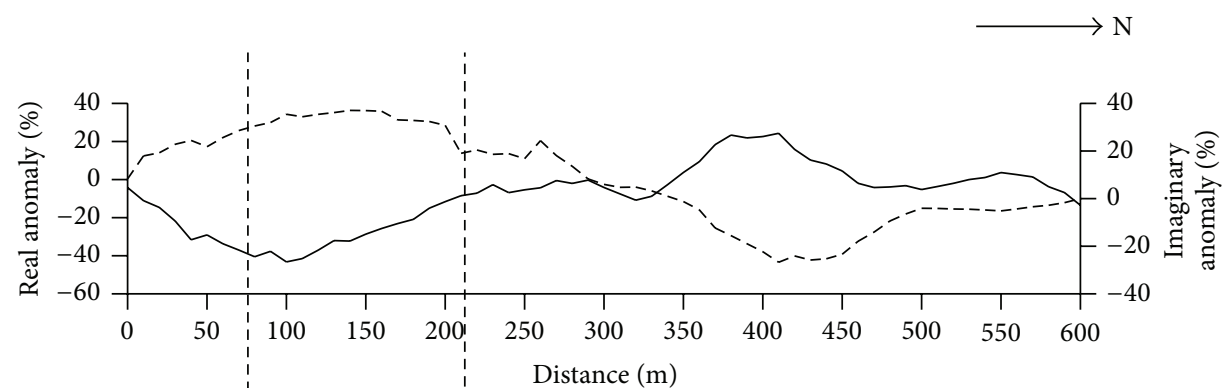

(a)

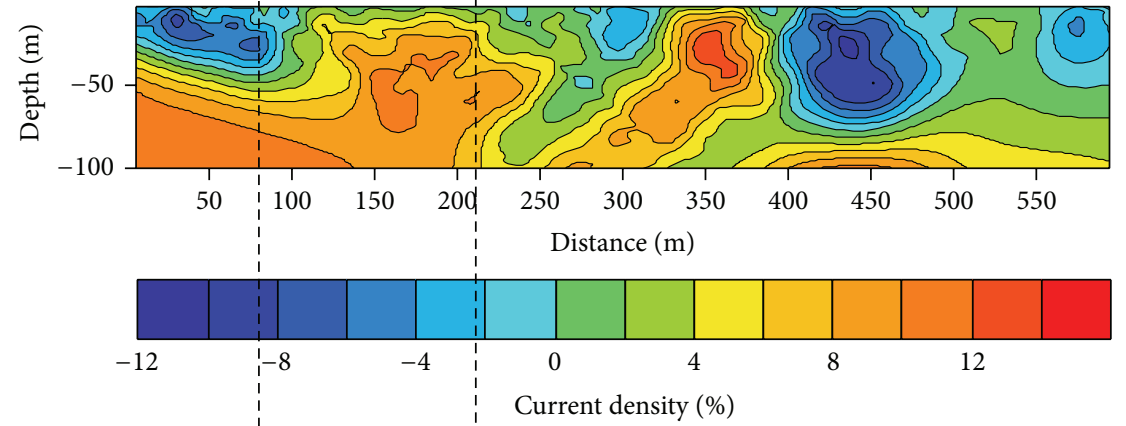

(b)

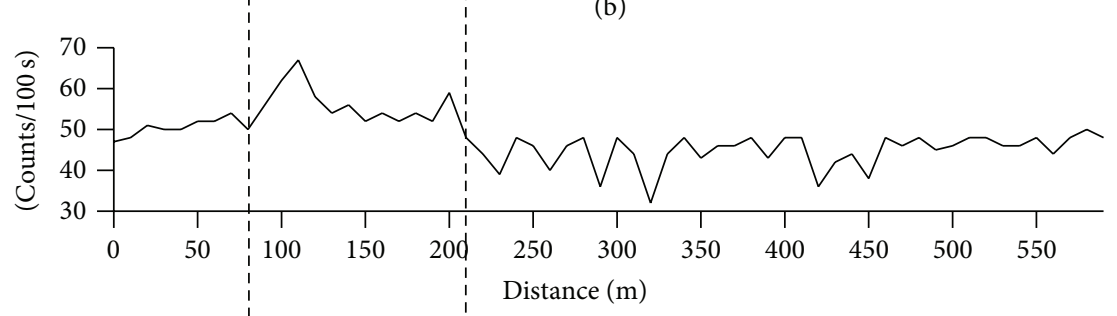

(c)

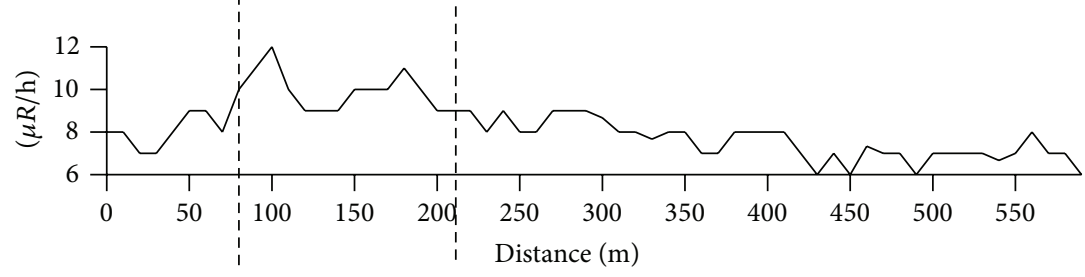

(d)

Figure 8: Profile P1700: (a) VLF anomaly (real by solid line and imaginary by dashed line), (b) pseudo current density cross-section along profile P1100, and (c) surface radiation and (d) surface gamma activity.

The current density contours along this profile clearly demarcates the shape of this body between stations $510 \mathrm{~m}$ and $570 \mathrm{~m}$, suggesting a width of around $60 \mathrm{~m}$, occurring below $30 \mathrm{~m}$ from the surface. Radiometric data recorded over this profile shows similar behavior as that at profile P1100, with peak values at $520 \mathrm{~m}$.

5.3. Profile 3 (P1300). This profile, $\mathrm{P} 1300$ (Figure 4), is further $83 \mathrm{~m}$ east of profile P1200. The real and imaginary anomaly plots indicate the presence of multiple conductive bodies along this profile and the slope of these curves suggests vertical structures occurring near to the surface. Apparent current density cross-section also depicts the same result, showing the presence of three broad and shallow, almost vertical conductors between stations $0 \mathrm{~m}$ and $60 \mathrm{~m}, 160 \mathrm{~m}$ and $250 \mathrm{~m}$, and $375 \mathrm{~m}$ and $450 \mathrm{~m}$. Similarly, the radioactivity along this profile is higher than the background throughout the profile, with peak between $410 \mathrm{~m}$ and $440 \mathrm{~m}$. The peak value of total radiations and surface gamma activity recorded at this station is 75 counts $/ 100 \mathrm{sec}$ and $19 \mu \mathrm{R} / \mathrm{h}$, respectively.

5.4. Profile 4 (P1400). Profile P1400 lies $92 \mathrm{~m}$ east of profile P1300 (Figure 5). Here, also, the VLF anomaly curves depict three conductive features, all being shallow and nearly 


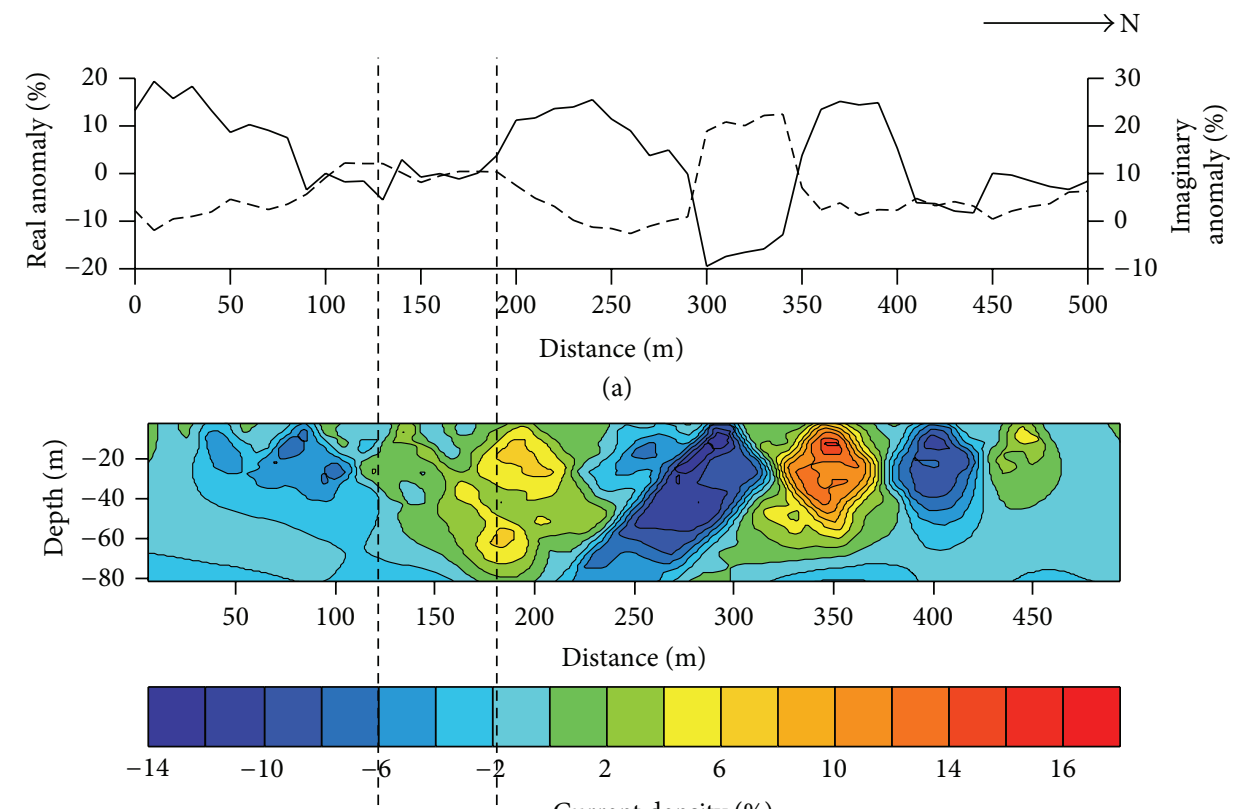

(b)

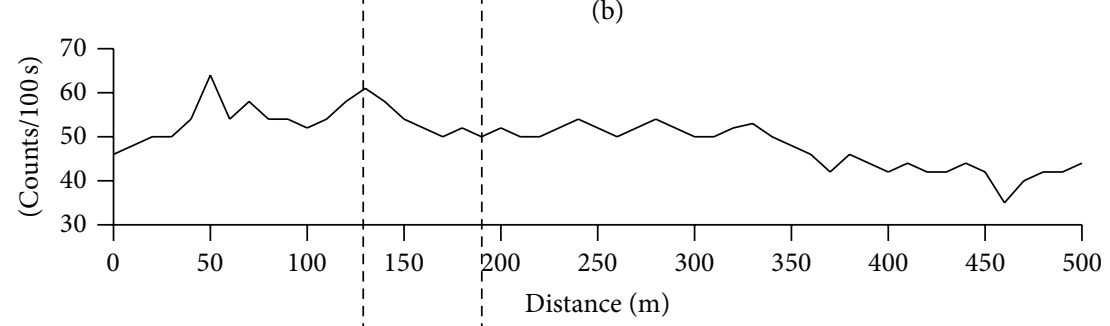

(c)

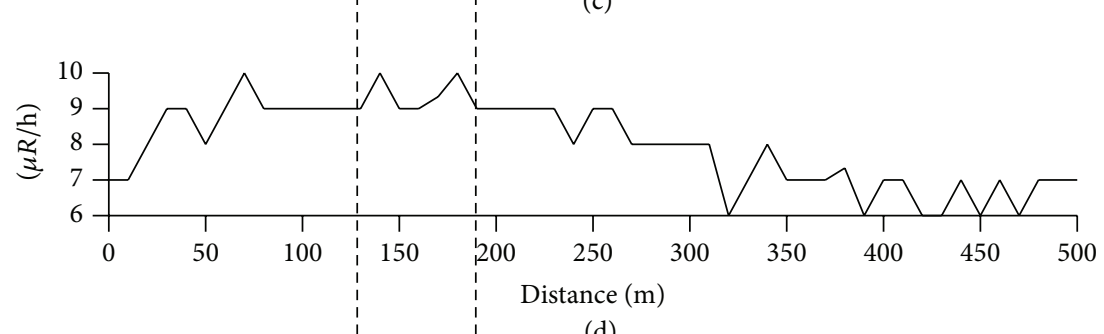

(d)

FIGURE 9: Profile P1800: (a) VLF anomaly (real by solid line and imaginary by dashed line), (b) pseudo current density cross-section along profile P1100, and (c) surface radiation and (d) surface gamma activity.

vertical. Apparent current density cross-section shows the presence of one conducting and two low conducting structures between stations $70 \mathrm{~m}$ and $140 \mathrm{~m}, 270 \mathrm{~m}$ and $320 \mathrm{~m}$, and $490 \mathrm{~m}$ and $520 \mathrm{~m}$, respectively. The conductor at the southern part of the profile (between stations $70 \mathrm{~m}$ and $140 \mathrm{~m}$ ) is more conductive and wider among the three. Radioactivity is observed to be highest above this conductor, with peak value of total radiation being 290 counts $/ 100 \mathrm{sec}$ and that of gamma activity being $60 \mu \mathrm{R} / \mathrm{h}$ at station $150 \mathrm{~m}$. This is the highest radioactivity recorded along all the profiles.

5.5. Profile 5 (P1500). Profile P1500 is taken $86 \mathrm{~m}$ away towards east of profile P1400 (Figure 6). VLF anomaly curves suggest the presence of a single conductor around station $400 \mathrm{~m}$. The slope of the anomaly curves indicates a thick inclined structure. Apparent current density cross-section confirms the presence of inclined conductive structure between stations $330 \mathrm{~mm}$ to $420 \mathrm{~m}$. Radiometric data is observed to be almost equal to the background levels all long the profile with a sudden jump in value to 180 counts/100 sec of total radiations and $35 \mu \mathrm{R} / \mathrm{h}$ surface gamma activity at station $510 \mathrm{~m}$.

5.6. Profile 6 (P1600). This profile is located in the western side of the Beldih mine (Figure 7). VLF anomaly curves indicate the presence of two conductive features around stations 


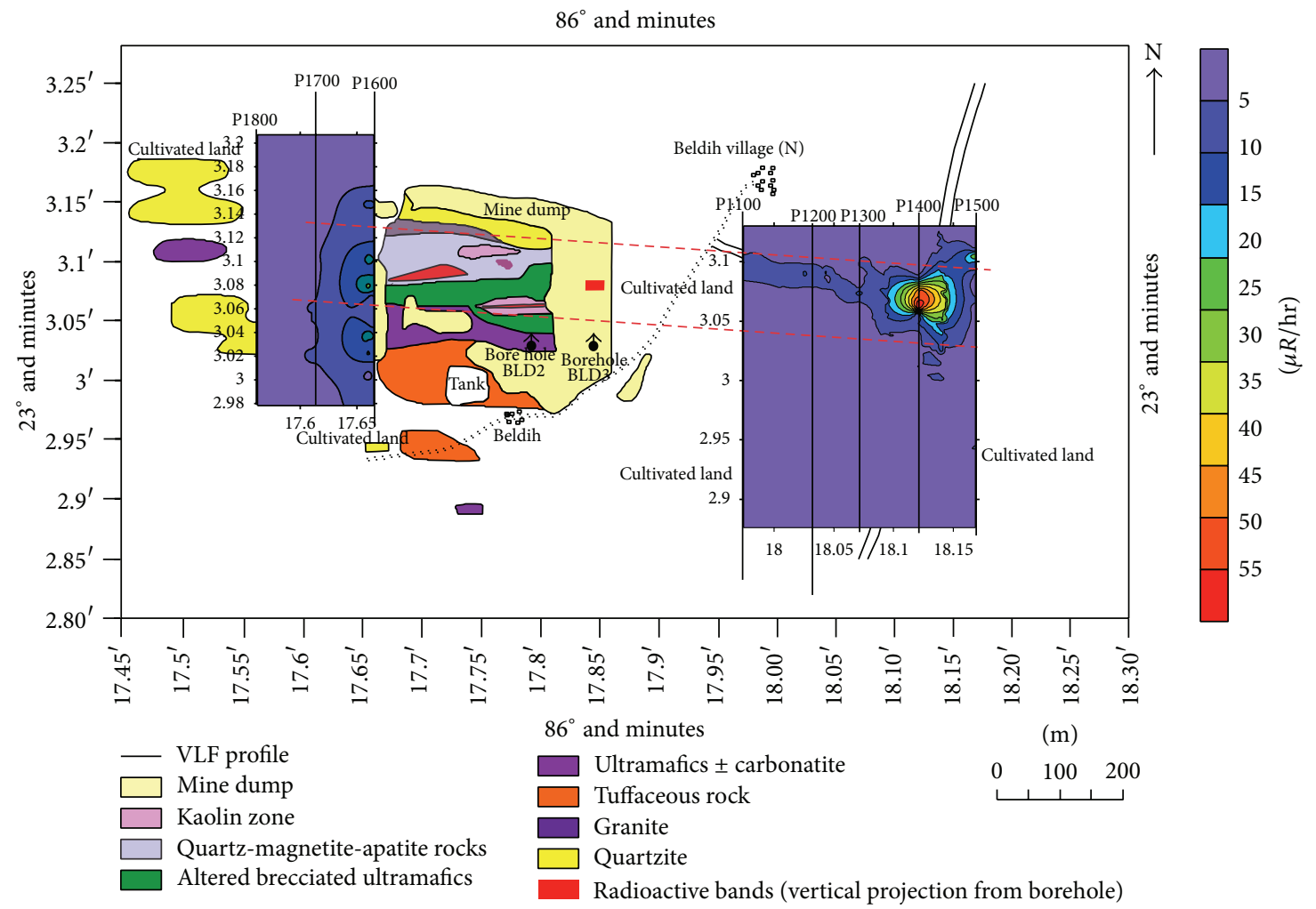

FIGURE 10: Surface gamma activity superimposed over geological map of the area of study.

Transverse section through bore hole BLD2

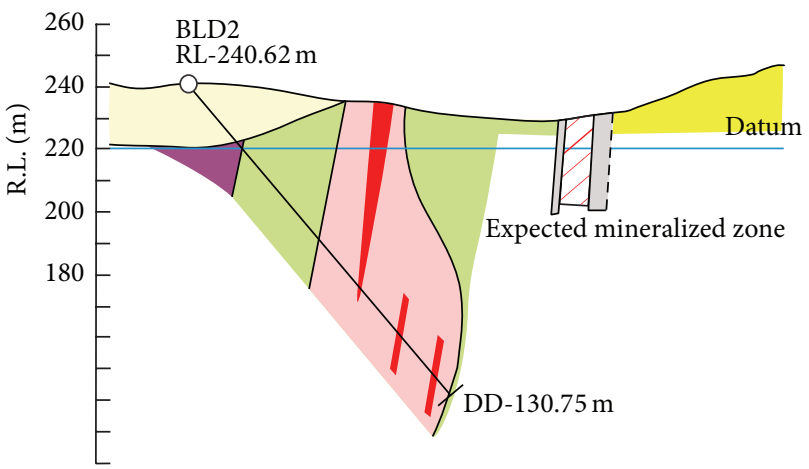

$\square$ Overburden/mine dump $\square$ Ultramafics \pm carbonatite
$\square$ Radioactive mineralization $\square$ Quartz-magnetite-apatite rock
$\square$ Kaolin zone
$\begin{aligned} & \text { Altered brecciated ultramafics } \\ & \square \text { Quartzite }\end{aligned}$
Transverse section through bore hole BLD3
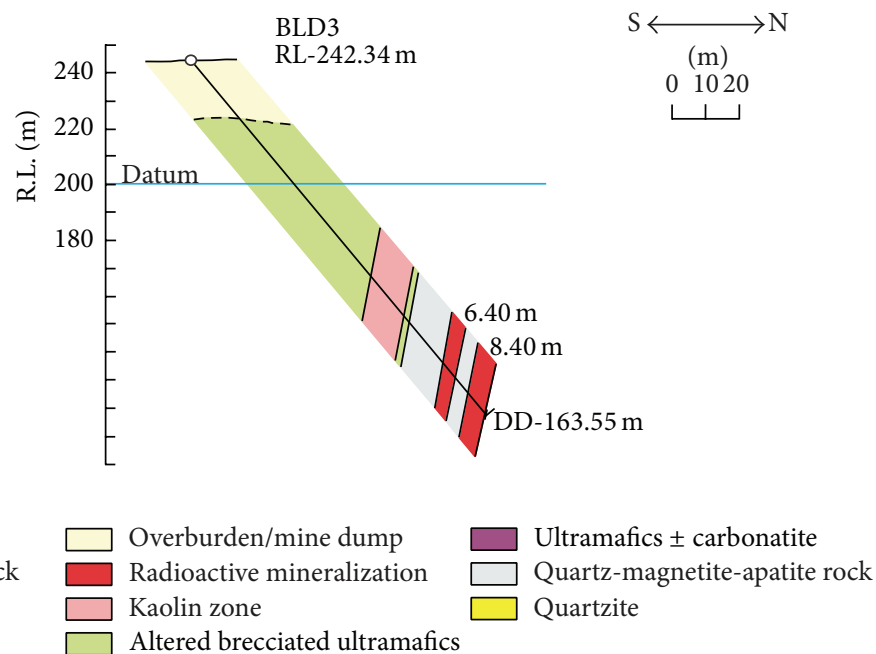

FIgURE 11: Transverse sections through bore holes BLD2 and BLD3 (after [7]).

$200 \mathrm{~m}$ and $450 \mathrm{~m}$. Apparent current density cross-section depicts both of the structures between stations $150 \mathrm{~m}$ and $250 \mathrm{~m}$, and $410 \mathrm{~m}$ and $520 \mathrm{~m}$ and shows that they are dipping structures. Radiometric data shows high radioactivity in the southern side of the profile compared to the northern side, with peak value of total radiation and gamma activity (140 counts $/ 100 \mathrm{sec}$ and $28 \mu \mathrm{R} / \mathrm{h}$, resp.) found above the station $250 \mathrm{~m}$.
5.7. Profile 7 (P1700). Differing from all other profiles, in profile P1700, $92 \mathrm{~m}$ west of P1600 (Figure 8), the VLF anomaly curves indicate a single wide conductive feature lying all over the profile, with centre at $350 \mathrm{~m}$. Apparent current density cross-section also shows a much wider conductive feature lying between $0 \mathrm{~m}$ and $230 \mathrm{~m}, 250 \mathrm{~m}$ and $370 \mathrm{~m}$, and $390 \mathrm{~m}$ and $500 \mathrm{~m}$, ranging in current density values from $4 \%$ to $10 \%, 4 \%$ to $12 \%$, and $4 \%$ to $8 \%$, respectively. This shows that, 
here, the same conducting zone is wider than other locations. Whereas, radiometric data suggests high radioactivity, above the background level, only between stations $70 \mathrm{~m}$ and $210 \mathrm{~m}$.

5.8. Profile 8 (P1800). Further $88 \mathrm{~m}$ west of P1700, in profile P1800 (Figure 9), VLF anomaly curves indicate the presence of two vertical conductors. Current density contours also show two conductive features between stations $160 \mathrm{~m}$ and $220 \mathrm{~m}$ and $320 \mathrm{~m}$ and $370 \mathrm{~m}$. The first one is less conductive as compared to the later one. Radiometric data indicates high radioactivity in the southern part of the profile with three peak regions around stations $50 \mathrm{~m}, 140 \mathrm{~m}$, and $180 \mathrm{~m}$.

\section{Discussion}

In the present study, eight profiles were chosen on either side of the Beldih mine to investigate the uranium and/or thorium mineralization by applying VLF-EM and radiometric methods together. Results show the presence of multiple isolated conductive features in the study area. These conductive features appearing in the profile could be because of the presence of fractures filled with fluids, hydrothermal alteration zones, clay mineralization, shearing, and so forth. The conductive features are traced continuously well in all the profiles, showing a regular parallel trend except in profile P1400 where the similar zone is identified in the southern side of the profile. This implies that the conductive feature at P1400 has shifted southward in this profile only. This offset of the current density anomaly (in profile P1400) could be due to either strike slip fault or dip slip fault or subparallel faulting. In case of dip slip fault, such offset can be observed only if an inclined bed is cut by a vertical fault at right angles to the strike and the slip is normal. After erosion, such an offset can be seen. However, the observed anomalies appear vertical in the current density profile and the offset or movement is lateral along the strike of the fault. This happens in case of strike-slip fault; hence, it appears to be the better reason for such lateral shift of the mineralized body. This can be further substantiated by successive structural mapping of the area.

The separation between the conductive bodies is not uniform along all the profiles. This further suggests that these mineralized bodies have small strike length and lenticular shape. This result together with the geology of the area indicates that the mode of mineralization may be hydrothermal alteration.

Radiometric measurements indicate higher radiations along the profiles than the average or background radiations observed in the area. The peak or elevated radiations indicate the presence of uranium mineralization.

Surface gamma activity superimposed over geological map of the area of study (Figure 10) clearly depicts the coincidence of conductive zones and high radioactivity zones. This coincidence indicates the existence of alteration zones in this area. These zones may contain radioactive mineralization as they are also correlating with the radioactive bands identified by Katti et al. [7] and with the bore hole data BLD2 and BLD3 (Figures 10 and 11). All these identified mineralized zones are almost parallel and have a collective strike oriented along E$\mathrm{W}$ direction which is in agreement with the strike of SPSZ.

\section{Conclusions}

VLF-EM and radiometric methods were applied together in this region to study the correlation between these two methods as well as to utilize their integrated results for the exploration of uranium. Results indicate good correlation between VLF data and radiometric data. This is because these radiometric signals are associated with shallow uranium mineralization which is associated with altered minerals that gives conductivity contrast with the neighboring rocks. Coincidence of high radioactivity over conductive zones and their correlation with radioactive bands observed in the area confirms the presence of uranium mineralization. Thus, the study also suggests that these two methods can be integrated to explore uranium and/or thorium mineralization effectively at low cost with the advantage of being quick and nondestructive compared to other routine methods used for such purposes. The study also reveals the presence of a strikeslip fault in the eastern side of the Beldih mine, proving the ability and advantage of this integrated approach in detecting such planner structures and correlating the lithology both vertically and laterally. Since, these methods are quick and cost effective; they can be utilized to search for shallow uranium mineralization along the SPSZ and other such regions quickly. VLF observations are sometimes affected by power lines, in such areas Gradient Resistivity Profiling and gravity and magnetic methods can be applied to aid in the interpretation of subsurface structures.

\section{Conflict of Interests}

The authors declare that there is no conflict of interests regarding the publication of this paper.

\section{Acknowledgments}

The authors would like to thank the editor and anonymous reviewers for their valuable comments and suggestions to improve the quality of the paper.

\section{References}

[1] B. K. Bhaumik, T. Bhattacharya, A. A. P. S. R. Acharyulu, D. Srinivas, and M. K. Sandilya, Principles of Radiometry in Radioactive Metal Exploration, Physics Lab, AMD Complex, Jamshedpur, India, 2004.

[2] V. Tuncer, M. J. Unsworth, W. Siripunvaraporn, and J. A. Craven, "Exploration for unconformity-type uranium deposits with audiomagnetotelluric data: a case study from the McArthur River mine, Saskatchewan, Canada," Geophysics, vol. 71, no. 6, pp. B201-B209, 2006.

[3] J. M. Legault, D. Carriere, and L. Petrie, "Synthetic model testing and distributed acquisition dc resistivity results over an unconformity uranium target from the Athabasca Basin, northern Saskatchewan," The Leading Edge, vol. 27, no. 1, pp. 46$51,2008$. 
[4] G. Nimeck and R. Koch, "A progressive geophysical exploration strategy at the Shea Creek uranium deposit," The Leading Edge, vol. 27, no. 1, pp. 52-63, 2008.

[5] A. Mandal, A. Biswas, S. Mittal et al., "Geophysical anomalies associated with uranium mineralization from Beldih mine, South Purulia Shear Zone, India," Journal of the Geological Society of India, vol. 82, no. 6, pp. 601-606, 2013.

[6] S. P. Sharma, A. Biswas, and S. Mittal, "Delineation of extension of uranium mineralization zone using resistivity and VLFsurveys around South Purulia Shear Zone, India," Journal of the Geological Society of India. In press.

[7] V. J. Katti, J. Sen, and A. K. Bhatt, "Uranium potentiality of South Purulia Shear Zone in Eastern Indian Shield," in Proceedings of the Technical Meeting on Low Grade Uranium Ore, pp. 29-31, International Atomic Energy Agency, Vienna, Austria, 2010.

[8] A. Acharyya, S. Ray, B. K. Chaudhuri, S. K. Basu, S. K. Bhaduri, and A. K. Sanyal, "Proterozoic rock suites along South Purulia Shear Zone, eastern India: evidence for rift-related setting," Journal of the Geological Society of India, vol. 68, no. 6, pp. 10691086, 2006.

[9] Y. Vapnik, S. Bushmin, A. Chattopadhyay, and D. DolivoDobrovolsky, "Fluid inclusion and mineralogical study of veintype apatite ores in shear zones from the Singhbhum metallogenetic province, West Bengal, India," Ore Geology Reviews, vol. 32, no. 1-2, pp. 412-430, 2007.

[10] T. K. Baidya, "Apatite-magnetite deposit in the chhotanagpur gneissic complex, Panrkidih area, Purulia District, West Bengal," Indian Journal of Geology, vol. 64, pp. 88-95, 1992.

[11] S. K. Basu, "Alkaline-carbonatite complex in Precambrian of South Purulia Shear Zone, eastern India: its characteristics and mineral potentialities," Indian Minerals, vol. 47, no. 3, pp. 179194, 1993.

[12] A. K. G. Roy and P. R. Sengupta, "Alkalic-carbonatitic magmatism and associated mineralisation along the Porapahar-Tamar lineament in the Proterozoics of Purulia District, West Bengal," Indian Journal of Earth Sciences, vol. 20, no. 3-4, pp. 193-200, 1993.

[13] T. K. Pyne, "The Proterozoic fold belt and the chhotanagpur gneissic complex in the eastern Indian Shield-a tectonometamorphic appraisal," Indian Minerals, vol. 46, no. 1, pp. 2534, 1992.

[14] S. Bhattacharya, "Ductile shear Zone in Purulia, West Bengal," Indian Journal of Geology, vol. 61, pp. 172-178, 1989.

[15] B. D. Smith and S. H. Ward, "On the computation of polarization ellipse parameters," Geophysics, vol. 39, pp. 867-869, 1974.

[16] N. R. Paterson and V. Ronka, "Five years of surveying with the very low frequency-electro magnetics method," Geoexploration, vol. 9, no. 1, pp. 7-26, 1971.

[17] M. Karous and S. E. Hjelt, "Linear filtering of VLF dip-angle measurements," Geophysical Prospecting, vol. 31, no. 5, pp. 782794, 1983.

[18] A. T. Ramli, S. Sahrone, and H. Wagiran, "Terrestrial gamma radiation dose study to determine the baseline for environmental radiological health practices in Melaka state, Malaysia," Journal of Radiological Protection, vol. 25, no. 4, pp. 435-450, 2005. 

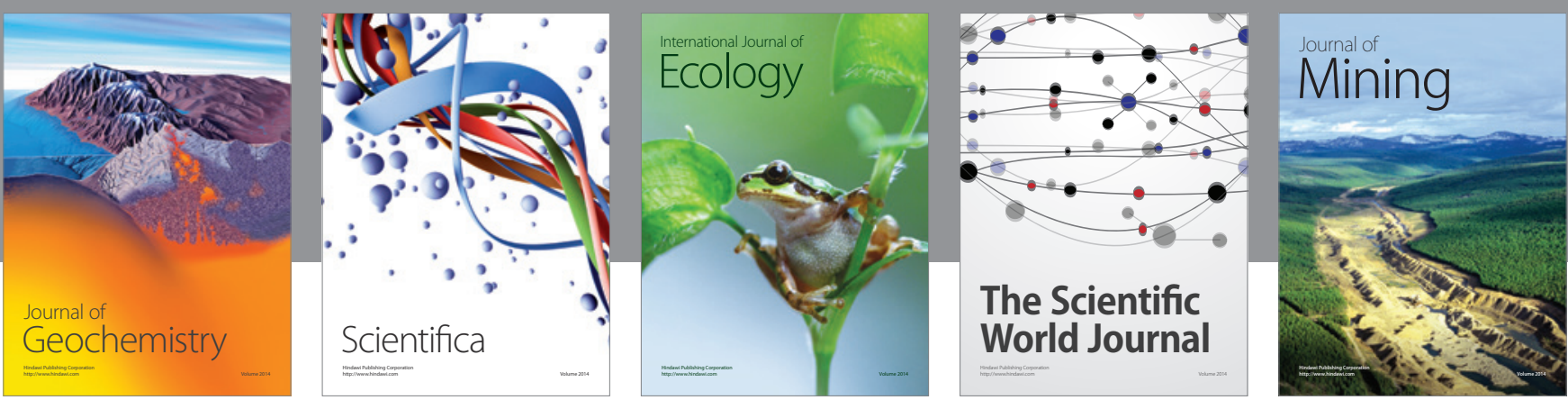

The Scientific World Journal
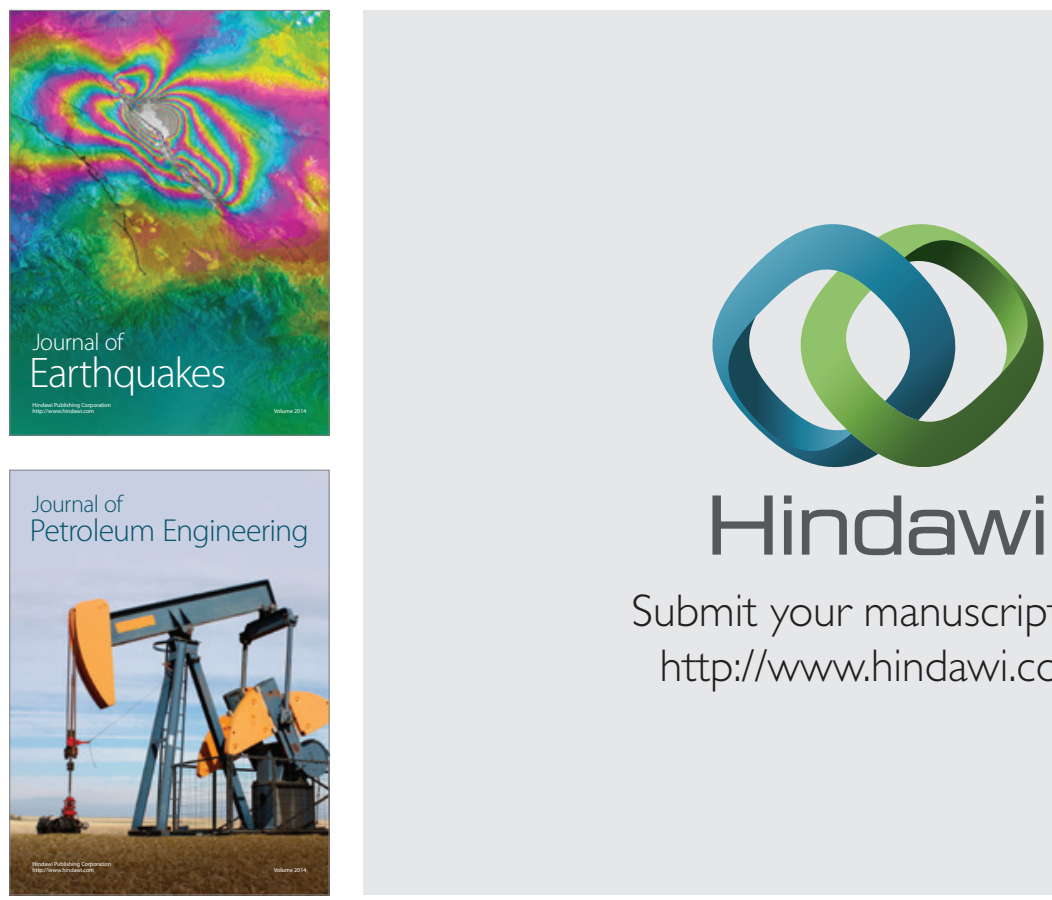

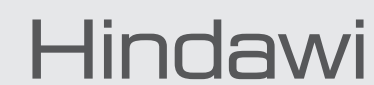

Submit your manuscripts at

http://www.hindawi.com
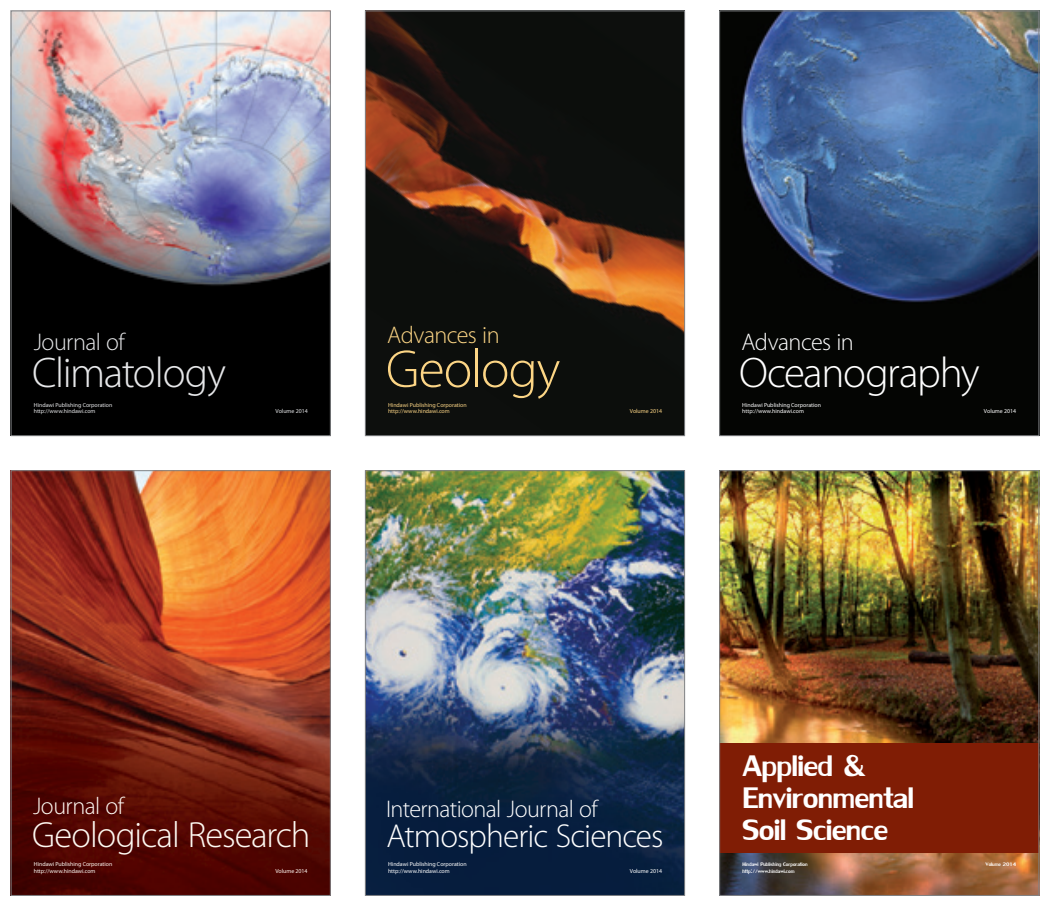
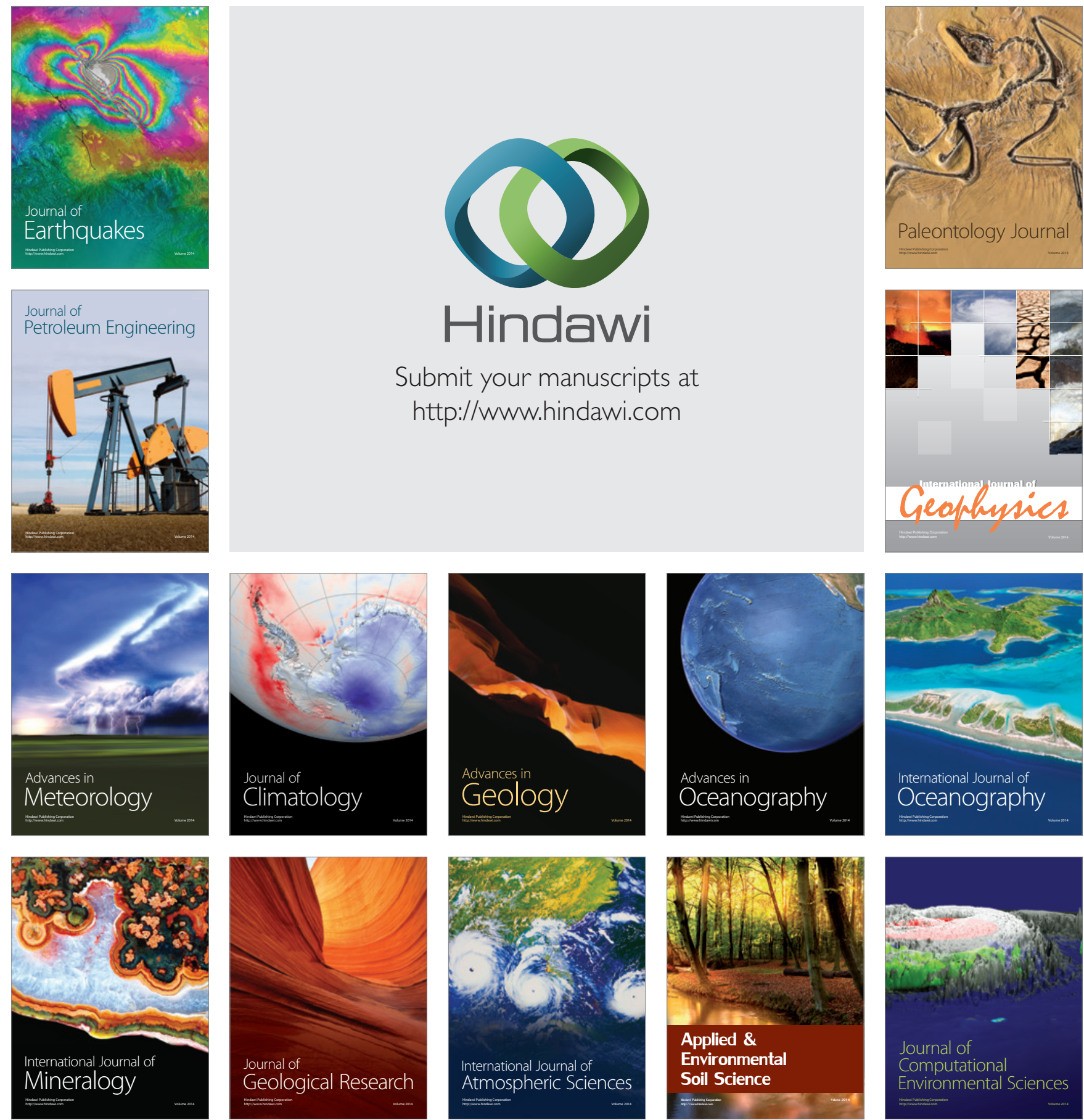